\title{
A study of empyema thoracis and role of intrapleural streptokinase in its management
}

\author{
Amit Banga1, GC Khilnani*1, SK Sharma1 ${ }^{1}$ AB Dey¹, Naveet Wig ${ }^{1}$ and \\ Namrata Banga ${ }^{2}$
}

\author{
Address: ${ }^{1}$ Department of Medicine, All India Institute of Medical Science, New-Delhi-110029, India and ${ }^{2}$ Department of Pharmacology, Lady \\ Hardinge Medical College, New-Delhi-110001, India \\ Email: Amit Banga - amit_banga@hotmail.com; GC Khilnani* - gckhil@hotmail.com; SK Sharma - sksharma@aiims.ac.in; \\ AB Dey - abdey@medinst.ernet.in; Naveet Wig - naveetwig@vsnl.com; Namrata Banga - namratabanga@yahoo.com \\ * Corresponding author
}

Published: 29 June 2004

BMC Infectious Diseases 2004, 4:19 doi:10.1186/1471-2334-4-19

This article is available from: http://www.biomedcentral.com/I47/-2334/4/19

(C) 2004 Banga et al; licensee BioMed Central Ltd. This is an Open Access article: verbatim copying and redistribution of this article are permitted in all media for any purpose, provided this notice is preserved along with the article's original URL.

\begin{abstract}
Background: Clinical spectrum, microbiology and outcome of empyema thoracis are changing. Intrapleural instillation of fibrinolytic agents is being increasingly used for management of empyema thoracis. The present study was carried out to describe the clinical profile and outcome of patients with empyema thoracis including those with chronic empyema and to study the efficacy and safety of intrapleural streptokinase in its management.
\end{abstract}

Methods: Clinical profile, etiological agents, hospital course and outcome of 31 patients (mean age $40 \pm 16$ years, M: F 25: 6) with empyema thoracis treated from 1998 to 2003 was analyzed. All patients were diagnosed on the basis of aspiration of frank pus from pleural cavity. Clinical profile, response to therapy and outcome were compared between the patients who received intrapleural streptokinase $(n=12)$ and those who did not $(n=19)$.

Results: Etiology was tubercular in $42 \%$ of the patients $(n=13)$ whereas the rest were bacterial. Amongst the patients in which organisms could be isolated $(n=13,42 \%)$ Staphylococcus aureus was the commonest $(n=5)$. Intrapleural streptokinase was instilled in 12 patients. This procedure resulted in increase of drainage of pleural fluid in all patients. Mean daily pleural fluid drainage after streptokinase instillation was significantly higher for patients who received intrapleural streptokinase than those who did not $(213 \mathrm{ml}$ vs $57 \mathrm{ml}, \mathrm{p}=0.006)$. Only one patient who was instilled streptokinase eventually required decortication, which had to be done in five patients (16.1\%). Mean hospital stay was $30.2 \pm 17.6$ days whereas two patients died.

Conclusions: Tubercular empyema is common in Indian patients. Intrapleural streptokinase appears to be a useful strategy to preserve lung function and reduce need for surgery in patients with late stage of empyema thoracis.

\section{Background}

Empyema thoracis refers to the collection of pus in the pleural cavity. There has been significant change in microbiology and course of empyema thoracis [1,2]. Despite availability and widespread usage of highly effective antibiotics, empyema thoracis occurs and is associated with significant morbidity and occasional mortality. Early drainage of pus from the pleural cavity along with broad- 
spectrum antibiotics is the cornerstone of treatment. Intercostal tube drainage (ICTD) is the usual mode of pus drainage. But ICTD is hampered by the presence of either thick pus, which tends to block the tube or the presence of multiple loculations that cannot be drained by a single chest tube. To overcome such problems surgical procedures like rib resection and open drainage were done in the past. These surgical procedures have been supplemented by safer and less invasive surgical procedures like video assisted thoracoscopic surgery (VATS) [3]. Although these surgical procedures have been a major step forward in search of lesser invasive approach for management of empyema thoracis, they still carry the risk of significant morbidity, lack free availability and costs involved remain prohibitive [4]. Use of fibrinolytic agents for intrapleural instillation has provided an option of managing these patients without subjecting them to surgical procedures. This therapeutic modality helps to break the loculations by virtue of its fibrinolytic property [5]. Although this approach has gained popularity in recent years, first use of fibrinolytic therapy was reported in 1949 [6]. But significant systemic side effects were seen at that time with use of unpurified fibrinolytic agents. This led to a loss of interest in the technique and it was only three decades later that a purified form of streptokinase was shown to improve outcome without causing any significant systemic side effects [7]. Since then, many studies have demonstrated the same to be a safe and effective strategy $[8,9]$.

Most of these studies evaluating the role of intrapleural streptokinase (IPSTK) have been comprised of patients with empyema at an early stage. The spectrum of patients with empyema thoracis in the Indian subcontinent is different from the West due to high prevalence of tubercular empyema. Because of this, a large number of patients tend to present with chronic empyema [10]. Data from India on utility of IPSTK in empyema thoracis is only limited to a few case reports $[11,12]$. Utility of IPSTK in a cohort comprising of significant number of patients with tubercular empyema has not been reported. Similar concerns were raised in a recent review as well [13].

This study was carried out with the goal of studying the safety and efficacy of this technique in Indian patients with empyema thoracis. We also describe the etiological agents, clinical features, hospital course and outcome of these patients.

\section{Methods}

Thirty one patients with empyema thoracis admitted to single medical unit of Department of Medicine of All India Institute of Medical Sciences (AIIMS), New Delhi, India (a tertiary care center) admitted over a 6-year period (1998 to 2003) were included in a retrospective fashion. All patients were admitted with a diagnosis of empyema thoracis secondary to different causes. Diagnosis of empyema thoracis was based on demonstration of frank pus upon pleural fluid aspiration prior to admission. None of the included patients was at the stage of nonempyematous complicated para-pneumonic effusion. Clinical profile in the form of history, associated co-morbid conditions, and physical examination, laboratory parameters including complete hemogram, serum chemistry, urine examination and hematological, biochemical and microbiological characteristics of pleural fluid were recorded. Serology (ELISA) for human immuno-deficiency virus (HIV) was done for all patients as described before [14].

Pleural fluid was examined for Gram stain, smear for acidfast bacilli (AFB) and cultured for pyogenic organisms and Mycobacterium tuberculosis (Lowenstein Jensen media) in all patients [15]. In addition to chest radiograph, computerized tomography (CT) of the chest was done for all patients. All patients were managed with insertion of ICTD. Except in cases where a large free collection was present, ICTD was inserted under ultrasound (US) guidance. Follow up US and/or CT chest were done and repositioning, removal or insertion of a second chest tube was carried out as per the need to achieve maximum drainage. Broad-spectrum antibiotics were also used. All patients received a combination of at least two or more antibiotics including metronidazole, third generation cephalosporins and cloxacillin. Four-drug anti-tuberculosis treatment (ATT) (rifampicin, isoniazid, pyrazinamide and ethambutol) was initiated in cases with tubercular etiology [16]. Daily drainage of pleural fluid from the pleural cavity was recorded for each patient.

As IPSTK was not used freely for management of patients with empyema thoracis in AIIMS during the initial years of the study, patients enrolled during that phase did not receive IPSTK $(n=19)$. Among the patients from the later years, IPSTK was routinely instilled $(n=12)$. Injection streptokinase (250,000 IU) (Thrombosolv, VHB life sciences, India) was dissolved in $100 \mathrm{ml}$ normal saline and instilled in the pleural cavity through the ICTD by clamping the distal end. After instillation, the tube was clamped for four hours and the patient asked to repeatedly change position and move around so that streptokinase (STK) could thoroughly spread in the pleural cavity. At the end of $4 \mathrm{hrs}$, the clamp was opened and amount of drainage, in addition to the saline instilled, was recorded. One cycle of IPSTK instillation comprised of three doses, each of 250,000 IU given every 12 hours, so that three doses of IPSTK were instilled by the next morning (at 0, 12, and 24 hours). Depending on the response and need, another cycle of three doses of 250,000 IU was initiated the next morning, thereby providing an interval of at least 24 hours between the two cycles. Such a schedule resulted in 
an average dose of 375,000 IU/day. All patients were closely watched for development of any side effects such as fever, chills, allergic reactions and bleeding. Evidence of hypersensitivity to STK (not seen in any patient) and presence of associated broncho-pleural fistula $(n=4)$ were contraindications for IPSTK instillation.

All other therapeutic strategies, both medical and surgical including decortication were recorded for all patients. In addition, days of hospital stay as well as survival to discharge was recorded.

\section{Statistical analysis}

Data were collected using a pre-designed data entry sheet. Data were double entered to minimize error and managed on a 'Microsoft Excel' spreadsheet. Analysis was done using statistical software 'SPSS version 10.0' (SPSS Inc, Chicago, IL, USA). Study group was divided in to IPSTK group (received IPSTK, $\mathrm{n}=12$ ) and non-IPSTK group (did not receive IPSTK, $n=19$ ) and various parameters were compared between the two groups. For continuous variables, normality of distribution was assessed. Normally distributed variables were summarized as mean with standard deviation and compared between the two groups using Student's t-test. Other continuous variables were described as median with range and compared using Mann-Whitney U test. Fisher exact test was applied to compare the ordinal variables. Statistical significance was considered at $P<0.05$ (only two tailed) for the present study.

\section{Results Clinical profile}

Mean age of the patients was $40 \pm 16$ years (range $15-80$ years). Males dominated the study group $(n=25,80.6 \%)$. Mean duration of symptoms was 144 days (range 3 days to 3 years). Diabetes mellitus was the commonest co-morbidity (5 patients, $16.1 \%$ ). Thirteen patients had evidence of underlying pulmonary tuberculosis $(42 \%)$. Rest of the patients had para-pneumonic effusion. Chest pain was the commonest symptom (90.3\%) followed by cough $(87.1 \%)$ and fever $(83.9 \%)$. Right side was more frequently involved ( $\mathrm{n}=17,54.8 \%)$ as compared to left side $(\mathrm{n}=12,38.7 \%)$. Two patients had bilateral empyema thoracis. Signs of volume loss on ipsilateral side (61.3\%) and clubbing (29\%) were common. Four patients had clinical evidence of associated broncho-pleural fistula. The clinical profile of IPSTK and non-IPSTK groups have been compared in Table 1.

\section{Laboratory profile}

Various laboratory parameters have been compared between the two groups (IPSTK and non-IPSTK group) in Table 1 . None of the parameters were significantly different between the two groups. Biochemical examination of pleural fluid revealed exudative nature of the fluid with low glucose in all patients. A majority of patients $(n=26$, $83.9 \%$ ) had neutrophil dominance in the pleural fluid whereas the rest had effusion with lymphocytic predominance $(n=5,16.1 \%)$. All patients were HIV sero-negative.

\section{Microbiological characteristics}

Organisms could be isolated from 13 patients out of which Staphylococcus aureus was the commonest (6 patients, 46.2\%). Rest of the patients grew gram-negative organisms, namely Pseudomonas aeruginosa $(\mathrm{n}=5)$, Klebsiella pneumoniae $(\mathrm{n}=4)$ and Escherichia coli $(\mathrm{n}=2)$. More than one organism was isolated in four patients. Smear as well as culture for Mycobacterium tuberculosis was negative for all patients. None of the patients grew any organism in blood or sputum cultures.

\section{Imaging}

CT chest was done for all patients. Loculations with pleural enhancement were seen in all patients. Prominent loss of lung volume on the side of empyema thoracis was seen in 20 patients $(64.5 \%)$. Parenchymal lesions suggestive of pulmonary tuberculosis were seen in 13 patients $(42 \%)$. These lesions consisted of typical fibro-parenchymal lesions with evidence of cavitation in apical regions of the lung suggestive of active disease. In addition, presence of mediastinal lymphadenopathy with central necrosis was seen in eight patients. Response to IPSTK was studied in all patients who received STK by a repeat CT chest. Radiological improvement in the form of reduction is the size of collection and partial to complete expansion of the underlying lung was seen in all patients.

\section{Treatment}

All patients received a combination of antibiotics. Metronidazole was used in $70 \%$ of the patients followed by cephalosporins and aminoglycoside in 58\% patients and cloxacillin in $48 \%$ patients. Thirteen patients (42\%) were given ATT. All were treated on the basis of pulmonary parenchymal lesions strongly suggestive of active tuberculosis and/or mediastinal lymphadenopathy with central necrosis on CT chest. ICTD was done for all patients. IPSTK was instilled in 12 patients. This procedure resulted in increase of pleural fluid drainage in all the patients. Mean daily pleural fluid drainage after STK instillation was significantly higher for IPSTK group $(213 \mathrm{ml}$ vs $57 \mathrm{ml}$, $\mathrm{p}=0.006$, figure 1 ). Mean cumulative drainage of pleural fluid was also significantly higher for patients who received IPSTK ( $1665 \mathrm{ml}$ vs $800 \mathrm{ml}, \mathrm{p}<0.001)$. No significant difference in pleural fluid drainage was seen between patients with tubercular empyema and those with non-tubercular empyema. Only one patient in IPSTK group eventually required decortication, as compared to four in the other group ( $8.3 \%$ vs $21 \%, \mathrm{p}=\mathrm{NS}$ ). Mean hospital stay was $30.2 \pm 17.6$ days whereas 2 patients died. 
Table I: Characteristics of patients who received intrapleural streptokinase (IPSTK group, $n=12$ ) and those who did not (Non IPSTK group, $n=19$ )

\begin{tabular}{|c|c|c|c|}
\hline Parameters & IPSTK group $(n=12)$ & Non IPSTK group $(n=19)$ & $P$ value \\
\hline Age (years) & $40 \pm 15$ & $41 \pm 17$ & 0.87 \\
\hline Sex (male/female) & $9 / 3$ & $16 / 3$ & 0.53 \\
\hline Duration of symptoms (months)* & $2.0(0.2-12)$ & $1.5(0.1-36)$ & 0.49 \\
\hline Chronic Empyema & $9(75 \%)$ & II (57.9\%) & 0.32 \\
\hline Hemoglobin (gm/dL) & $10.1 \pm 2.6$ & $9.6 \pm 2.0$ & 0.63 \\
\hline $\operatorname{TLC}(/ \mathrm{cmm})$ & $11,100 \pm 5489$ & $|4,494 \pm 827|$ & 0.19 \\
\hline ESR ( $\left({ }^{\text {st }} \mathrm{hr}\right)$ & $46 \pm 19$ & $57 \pm 24$ & 0.17 \\
\hline Blood Urea $(\mathrm{mg} / \mathrm{dL})$ & $36 \pm 15$ & $41 \pm 21$ & 0.08 \\
\hline Serum creatinine (mg/dL) & $1.2 \pm 0.5$ & $1.3 \pm 0.8$ & 0.64 \\
\hline Serum sodium (meq/L) & $135.7 \pm 4 . \mid$ & $134.9 \pm 7.3$ & 0.69 \\
\hline Serum potassium (meq/L) & $4.3 \pm 0.8$ & $4.1 \pm 0.4$ & 0.38 \\
\hline Total bilirubin (mg/dL) & $0.6 \pm 0.3$ & $0.8 \pm 0.5$ & 0.06 \\
\hline AST (IU/L)* & $28(|7-2| 8)$ & $32(|2-38|)$ & 0.48 \\
\hline ALT (IU/L)* & $19(10-295)$ & $33(|0-46|)$ & 0.54 \\
\hline SAP (IU/L) & $203 \pm 110$ & $200 \pm 105$ & 0.95 \\
\hline Serum albumin (gm\%) & $2.9 \pm 0.7$ & $3.1 \pm 0.7$ & 0.54 \\
\hline PI F total cells $(/ \mathrm{cmm})^{*}$ & $5000(500-90,000)$ & $2500(800-160,000)$ & 0.25 \\
\hline PI F neutrophil count $(/ \mathrm{cmm})^{*}$ & $4500(500-85,000)$ & $2000(100-150,000)$ & 0.21 \\
\hline PI F protein (gm/dL) & $4.9 \pm 1.1$ & $4.4 \pm 1.8$ & 0.29 \\
\hline PI F glucose (mg/dL)* & $32(0-80)$ & $12(3-70)$ & 0.17 \\
\hline Presence of loss of lung volume & $8(66.7 \%)$ & $12(63.2 \%)$ & 0.84 \\
\hline Tubercular empyema & $6(50 \%)$ & $7(36.8 \%)$ & 0.47 \\
\hline
\end{tabular}

TLC: Total leukocyte count, ESR: Erythrocyte sedimentation rate, AST: Aspartate aminotransferase, ALT: Alanine aminotransferase, SAP: Serum alkaline phosphatase, PI F: Pleural fluid. Data is presented as mean \pm standard deviation except those variables marked by a $*$ where data is presented as median with range. †Patients with duration of symptoms more than 4 weeks were designated as having chronic empyema

Cause of death was refractory hypotension with extensive PTB in one patient and sepsis with multi-organ failure in other. These parameters were not different for the two groups.

\section{Discussion}

This retrospective study indicates the microbiology and changing trends in the management of empyema thoracis and emerging role of fibrinolytic therapy in management of empyema thoracis at a late stage. Organisms could be isolated from pleural fluid in $42 \%$ of patients. Rates of microbiological diagnosis in earlier studies have been in the range of $31-72 \%[7,17]$, which are similar to what we found. Staphylococcus aureus was the commonest amongst the microbiological isolates. Rest of the isolates were gram-negative organisms. Many earlier reports from the West have indicated the rising incidence of Staphylococcus aureus as a cause of empyema thoracis [18] and the same seems to be true for patients from India as well. Gramnegative organisms are also frequently isolated, presumably, because of high incidence of resistance of these organisms to commonly used antibiotics in the early phase of pneumonia. None of the patients grew streptococci or any anaerobic organism. This also is in accordance with earlier reports where streptococci were rarely if ever seen as a cause of empyema $[18,19]$. More than one isolate was found in four patients (31\%). Polymicrobial etiology of empyema thoracis is also well documented [19]. This justifies the use of combination of antibiotics as an empirical form of treatment. On the basis of isolates in the present series, a combination of at least an anti-staphylococcal antibiotic with another antibiotic having activity against gram-negative organisms seems to be appropriate. A large percentage of patients $(58 \%)$ received aminoglycosides. This is somewhat unexpected, as penetration of aminoglycosides in the pleural space is known to be poor [20]. Many of these patients would have received aminoglycosides for other indications such as underlying pneumonia. In addition, this pattern of use probably reflects the problems related to the treatment costs. Most of the patients admitted to our center are from low socio-economic strata and are not able to afford costly drugs such as cephalosporins and the same are not available freely in the hospital supply. In most of these cases, aminoglycosides would be given for providing gram-negative coverage.

Tubercular etiology was found in 13 patients (42\%). This is higher as compared to an earlier series from India. Gupta and coworkers [2] reported an incidence of $29 \%$ in 1989. But it was also observed that this was significantly 


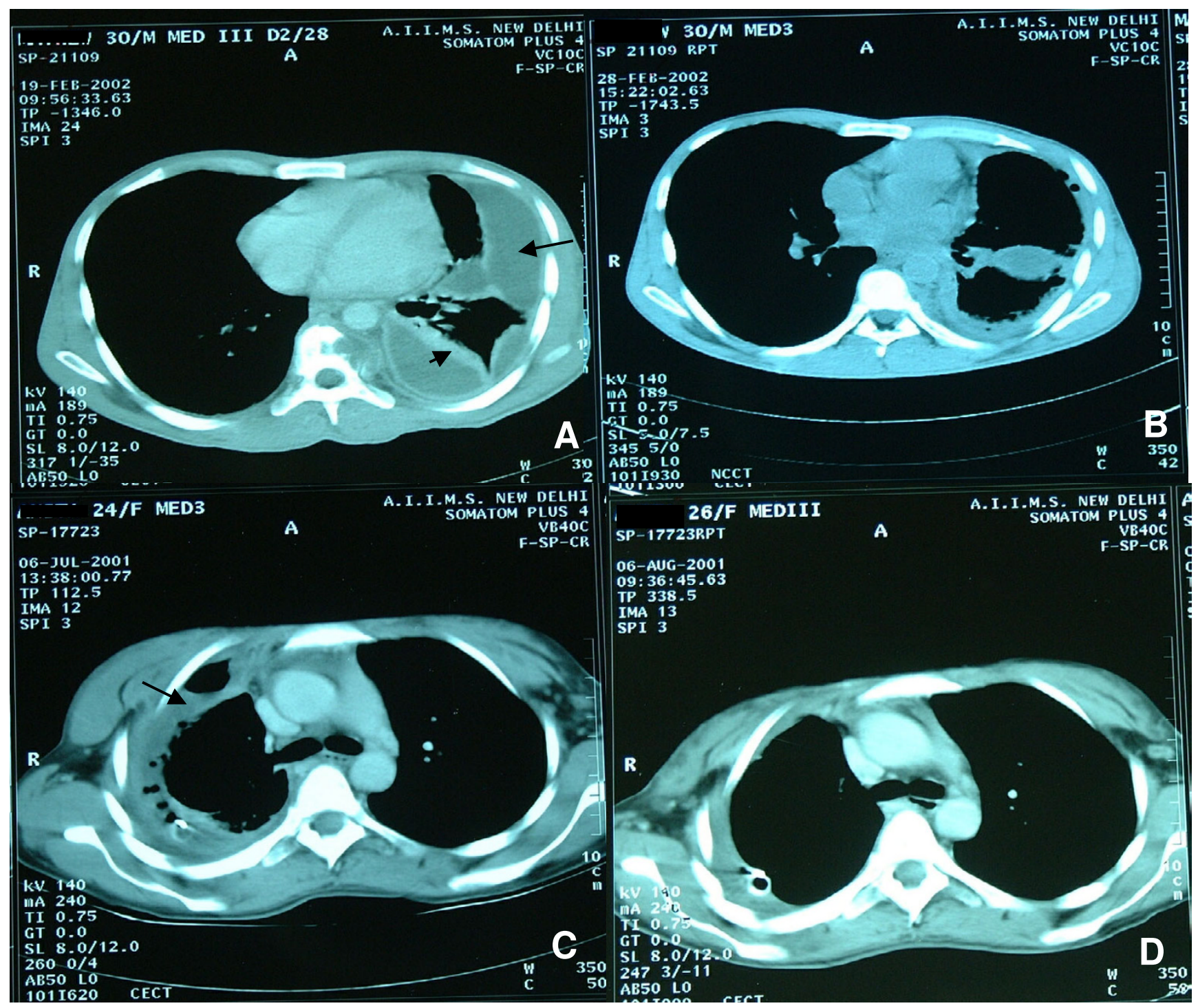

\section{Figure 2}

(A) CT chest of patient with loculated empyema thoracis (arrow) and (B) marked resolution following intrapleural streptokinase therapy. (C) Empyema thoracis and (D) significant improvement after intrapleural streptokinase therapy in another patient.

lower than what had been reported in various earlier reports from 1970-1985 [1,10,22] where tuberculosis was responsible for majority of the patients with empyema thoracis. Mycobacterium tuberculosis could not be isolated from any of the patients with tubercular empyema. All these patients were diagnosed on the basis of radiological features like pulmonary fibro-parenchymal lesions $(n=13)$ or necrotising lymphadenopathy ( $n$ $=8$ ). In contrast to figures from the West where isolation rates of Mycobacterium tuberculosis from pus have been very high, Indian studies have consistently reported low isola- tion rates. Jha and coworkers (1972) [1] found AFB in empyema fluid in only 1 out of 24 patients $(4.2 \%)$ whereas in a relatively recent series, AFB could not be isolated from any of the 29 patients with tubercular empyema [10]. The cause of this phenomenon is not clear and needs further evaluation.

The main aim of this report was to study the utility of IPSTK in patients with empyema thoracis from a region where chronic empyema is common. This is an important exercise as IPSTK has been shown, predominantly, to be 


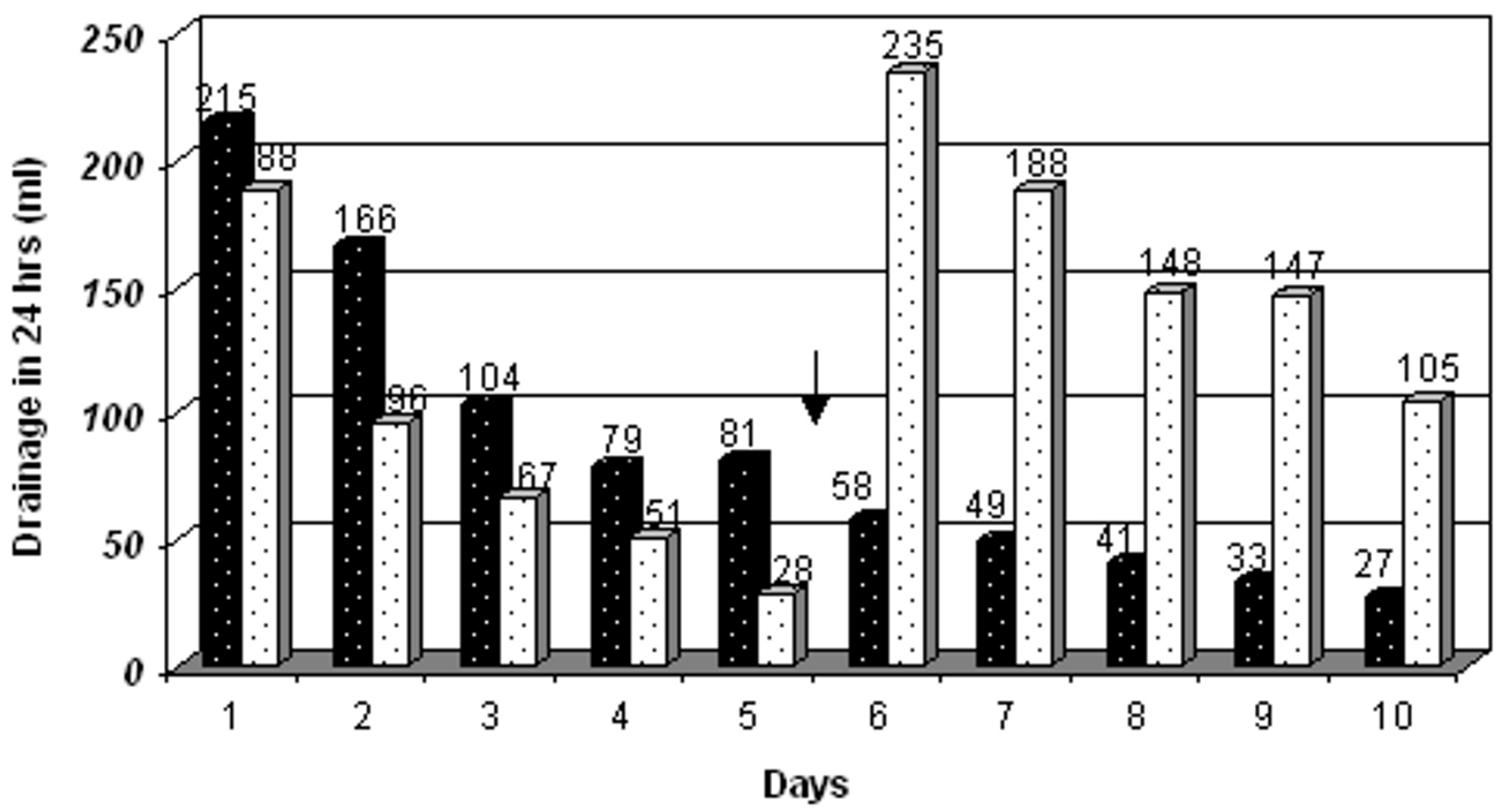

no IPSTK (n=19) DIPSTK (n=12)

\section{Figure I}

Mean pleural fluid drainage 5 days before and 5 days after intrapleural streptokinase (IPSTK) instillation for the two groups, $\downarrow$ :time of starting streptokinase instillation

effective in acute empyema. Twelve patients in whom loculations had been demonstrated on CT chest received IPSTK. It was demonstrated that IPSTK was consistently associated with marked increase in the pleural fluid drainage. All patients who received STK had been on ICTD alone, to start with, before loculations could be demonstrated on CT chest (mean duration on ICTD alone prior to instillation of IPSTK: 5.2 days; range: 4-7 days). Because of this, increase in drainage following instillation of STK could be quantitated and radiologically documented. (Figure 1 \&2). On the other hand, drainage of those patients who did not receive STK showed a gradual decline (Figure 1). In addition, requirement of a surgical procedure was reduced in patients who received STK. Similar finding was also reported by Davies et al [8] although Chin and Lim [9] did not find any such advantage.
Many authors have reported the efficacy and safety of intra-pleural fibnrinolytic agents (Table 2) [8,9,23-31]. In addition to substantiating the same findings, the present study serves to document the efficacy of IPSTK in a particular subset of patients. Till now, the use of STK has been mostly restricted to patients with empyema in the early phase of the disease. This is the stage of complicated parapneumonic effusion when loculations have just formed and fibrin peel is being laid on pleural surface. At this stage maximum breakdown of loculations and dissolution of fibrin peel is expected to occur. There is no doubt that this is the stage when fibrinolytic therapy appears to have the most desirable effect. Almost complete preservation of lung function can be expected. Nonetheless, the results of the present study indicate that IPSTK may also be useful in a late stage of empyema thoracis. That present study did include such patients is obvious from many factors including a long duration of illness prior to 
Table 2: Use of intrapleural streptokinase in empyema thoracis

\begin{tabular}{llll}
\hline Reference* & Number of patients & Number of instillations & Complications** \\
\hline Chin [8] & 17 & $1-10$ & None \\
Davies [9] & 7 & NA & None \\
Lysy [23] & 3 & $4-10$ & None \\
Willsie-Ediger [24] & 3 & $1-10$ & None \\
laye [25] & 9 & $1-4$ & Fever (3), chest wall erythema (2) \\
Alfageme [26] & 8 & NA & None \\
Bouros [27] & 5 & $3-10$ & Fever (I) \\
Taylor [28] & 11 & $2-6$ & None \\
Jerjes-Sanchez [29] & 30 & $2-10$ & Pleuritic pain (3), Fever (I) \\
Laisaar [30] & 21 & $2-8$ & Fever, bleeding \\
Roupie [3I] & 16 & $1-3$ & Chills and fever (I) \\
Present Study & 12 & $3-9$ & None
\end{tabular}

* Figures in square brackets denote the reference number ** Figures in parenthesis refer to the number of patients that developed the respective complication

admission in majority of the patients and a large number of patients with signs of volume loss on CT chest. Presence of a large number of patients with tubercular empyema (n $=13,42 \%$ ) in each group (IPSTK group 6/12 \& non-IPSTK group $7 / 19$ ) also supports the same fact. It appears that even in patients at a late stage of empyema, IPSTK resulted in significant breakdown of loculations (Figure 2A and $2 \mathrm{~B}$ ). The reason for this could be the higher dose of IPSTK used in this study. Also, even at a late stage of an active disease, new loculations are being formed which are likely to be lysed by STK. The use of IPSTK at the dose used in the present study (average dose 375,000 IU /day for 3-5 days) was not associated with any obvious systemic effects, although coagulation profile was not done for any patient. Therefore, we would like to suggest that in a patient who presents at a late stage of empyema thoracis, a trial of fibrinolytic therapy must be considered. In such patients a higher dose of IPSTK $(375,000 \mathrm{IU} /$ day $)$ may be given if drainage does not improve with 250,000 IU/day. These patients should undergo repeat imaging to evaluate the need for further instillation of STK as well as repositioning of chest tube if required. Such an approach is likely to yield the best results with maximum preservation of lung function and avoidance of any major surgical procedure. The relatively small sample size and retrospective design are drawbacks of the present study and the results need to be substantiated by a larger prospective trial in the future.

\section{Conclusions}

Empyema thoracis is associated with significant morbidity. Tubercular empyema is common in Indian setting but rates of isolation of Mycobacterium tuberculosis from pus are low. Corroborative evidence in the form of suggestive radiology is utilized for supporting the diagnosis. Even in patients with late stage of empyema thoracis, IPSTK appears to be a useful strategy to preserve lung function and reduce need for surgery.

\section{Competing Interests}

None declared.

\section{Author's Contributions}

AB: Concept and design of study, management of patients with instillation of intrapleural streptokinase, collection of data, analysis of data including statistical analysis and preparation of manuscript. GCK: Concept and design of study, management of patients, collection of data and manuscript preparation. SKS: Management of patients and manuscript preparation. ABD: Management of patients, concept and design of study. NW: Management of patients and manuscript preparation. NB: Preparation of the manuscript including statistical analysis.

\section{References}

I. Jha VK, Singh RB: Empyema of the thorax. Indian J Chest Dis 1972, 14:243-248.

2. Gupta SK, Kishan J, Singh SP: Review of one hundred cases of empyema thoracis. Indian J Chest Dis Allied Sci 1989, 3 I: 15-20.

3. Waller DA: Thoracoscopy in management of postpneumonic pleural infections. Curr Opin Pulm Med 2002, 8:323-6.

4. Weissberg D, Schachner A: Video-assisted thoracic surgery state of the art. Ann Ital Chir 2000, $71: 539-43$.

5. Bouros D, Schiza S, Siafakas N: Fibrinolytics in the treatment of parapneumonic effusions. Monaldi Arch Chest Dis 1999, 54:258-63.

6. Tillett WS, Sherry S: The effect in patients with streptococcal fibrinolysis (streptokinase) and streptococcal desoxyribonuclease on fibrinous, purulent, and sanguinous pleural exudations. J Clin Invest 1949, 28:173-190.

7. Bergh NP, Ekroth R, Larsson S, Nagy P: Intrapleural streptokinase in the treatment of haemothorax and empyema. Scand J Cardiovasc Surg 1977, II:265-268.

8. Davies RJO, Traill ZC, Gleeson FV: Randomized, controlled trial of intrapleural streptokinase in community-acquired pleural infection. Thorax 1997, 52:416-421.

9. Chin NK, Lim TK: Controlled trial of intrapleural streptokinase in the treatment of empyema and complicated parapneumonic effusions. Chest 1997, I I I:275-279. 
10. Aggarwal SK, Ray DC, Jha N: Empyema thoracis: A review of $\mathbf{7 0}$ cases. Indian J Chest Dis Allied Sci 1985, 27:17-22.

II. Sharma VP, Guleria R, Gupta R, Sharma SK, Pande JN: Intrapleural streptokinase in multiloculated empyema thoracis. J Assoc Physicians India 1998, 46:227-229.

12. Barthwal MS: Intrapleural streptokinase in a two-year-old child with a parapneumonic effusion. Indian J Chest Dis Allied Sci 200I, 43:165-168.

13. Khilnani GC: Fibrinolytic therapy for parapneumonic effusion and empyema. Indian J Chest Dis Allied Sci 2002, 44:8I-84.

14. Sharma SK, Aggarwal G, Seth P, Saha PK: Increasing HIV seropositivity among adult tuberculosis patients in Delhi. Indian J Med Res 2003, 1 17:239-42.

15. Balows A, Harsier WJ Jr: Manual of clinical microbiology; Section III 5th edition. Washington DC: American Society of Microbiology; 1991:209-553.

16. Neralla S, Glassroth J: Mycobacterium tuberculosis: the treatment of active disease. Semin Respir Infect 2003, 18:292-306.

17. Jain SK, Mishra RM, Gupta RK, Agarwal RL: Treatment of empyema thoracis by different conservative methods. Indian J Chest Dis Allied Sci 1981, 23:134-137.

18. Kelly JW, Morris MJ: Empyema thoracis: Medical aspects of evaluation and treatment. South Med J 1994, 87: I 103-I I09.

19. Delikaris PG, Conlan AA, Abramor E, Hurwitz SS, Studii R: Empyema thoracis-a prospective study on 73 patients. $S$ Afr Med J 1984, 65:47-49.

20. Hughes CE, Van Scoy RE: Antibiotic therapy of pleural empyema. Semin Respir Infect 1991, 6:94-102.

21. Agarwal SK, Ray DC, Jha N: Empyema thoracis: A review of $\mathbf{7 0}$ cases. Indian J Chest Dis Allied Sci 1985, 27: 17-22.

22. Tandon RK, Patney NL, Srivastava VK, Wadhawan VP: Empyema thoracis in infancy and childhood. Indian J Chest Dis 1972, I 4:258-26I.

23. Lysy Y, Werczberger A, Gavish A, Reifen R, Lieberson A, Dudai M: Intrapleural instillation of streptokinase in the treatment of organizing empyema. Isr J Med Sci 1989, 25:284-287.

24. Willsie-Ediger SK, Salzman G, Reisz G, Foreman MG: Use of intrapleural streptokinase in the treatment of empyema. Am J Med Sci 1990, 300:296-300.

25. laye RW, Froese DP, Hill LD: Use of purified streptokinase in empyema and hemothorax. Am J Surg 1991, 161:560-562.

26. Alfageme I, Munoz F, Pena N, Umbria S: Empyema of the thorax in adults. Etiology, microbiologic findings and management. Chest 1993, 103:839-843.

27. Bouros D, Schiza S, Panagou P, Drositis J, Siafakas N: Role of streptokinase in the treatment of acute loculated parapneumonic pleural effusions in empyema. Thorax 1994, 49:852-855.

28. Taylor RF, Rubens MB, Pearson MC, Barnes NC: Intrapleural streptokinase in the management of empyema. Thorax 1994, 49:856-9.

29. Jerjes-Sanchez C, Ramirez-Rivera A, Elizalde JJ, Delgado R, Cicero R, Ibarra-Perez C, Arroliga AC, Padua A, Portales A, Villarreal A, PerezRomo A: Intrapleural fibrinolysis with streptokinase as an adjunctive treatment in hemothorax and empyema. Chest 1996, 109:1514-9.

30. Laisaar T, Tuttsepp E, Laisaar V: Early administration of intrapleural streptokinase in the treatment of multiloculated pleural effusions and pleural empyemas. Thorac Cardiovasc Surg 1996, 44:252-6.

31. Roupie E, Bouabdallah K, Delclaux C, Brun-Buisson C, Lemaire F, Vasile N, Brochard L: Intrapleural administration of streptokinase in complicated purulent pleural effusion: a CT-guided strategy. Int Care Med 1996, 22:135I-I353.

\section{Pre-publication history}

The pre-publication history for this paper can be accessed here:

http://www.biomedcentral.com/1471-2334/4/19/prepub

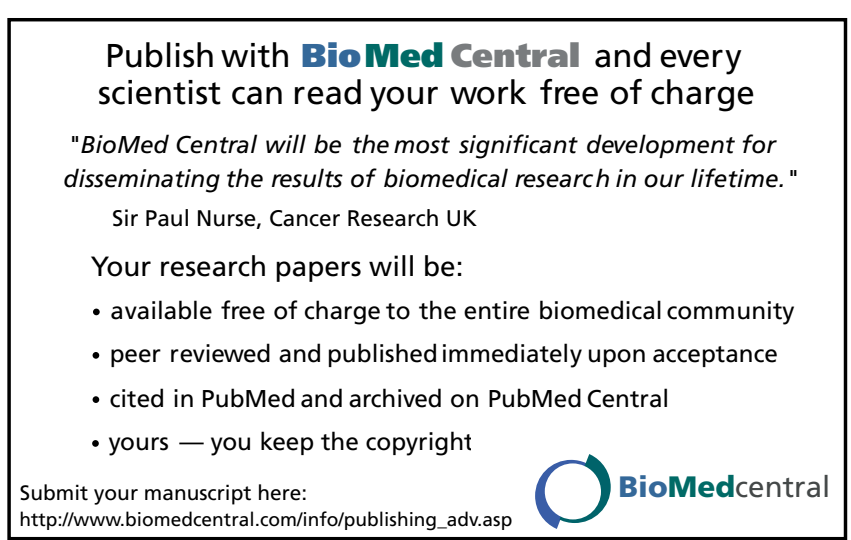

